\title{
Intensive oyster aquaculture can reduce disease impacts on sympatric wild oysters
}

\author{
Tal Ben-Horin ${ }^{1,2, *}$, Colleen A. Burge ${ }^{3}$, David Bushek ${ }^{4}$, Maya L. Groner ${ }^{5,6}$, \\ Dina A. Proestou ${ }^{2}$, Lauren I. Huey ${ }^{7}$, Gorka Bidegain ${ }^{8}$, Ryan B. Carnegie ${ }^{7}$ \\ ${ }^{1}$ Department of Fisheries, Animal and Veterinary Sciences, College of the Environment and Life Sciences, \\ University of Rhode Island, Kingston, RI 02881, USA \\ ${ }^{2}$ National Cold Water Marine Aquaculture Center, US Department of Agriculture Agricultural Research Service, Kingston, \\ RI 02881, USA \\ ${ }^{3}$ Institute of Marine and Environmental Technology, University of Maryland Baltimore County, Baltimore, MD 21202, USA \\ ${ }^{4}$ Haskin Shellfish Research Laboratory, Rutgers University, Port Norris, NJ 08349, USA \\ ${ }^{5}$ Prince William Sound Science Center, Cordova, AK 99574, USA \\ ${ }^{6}$ US Geological Survey Western Fisheries Research Center, Seattle, WA 98105, USA \\ ${ }^{7}$ Virginia Institute of Marine Science, College of William \& Mary, PO Box 1346, Gloucester Point, VA 23062, USA \\ ${ }^{8}$ Department of Applied Mathematics, University of the Basque Country, Bilbao, 48013 Bizkaia, Spain
}

\begin{abstract}
Risks associated with disease spread from fish and shellfish farming have plagued the growth and public perception of aquaculture worldwide. However, by processing nutrients and organic material from the water column, the culture of many suspension-feeding bivalves has been proposed as a novel solution toward mitigating problems facing coastal water quality, including the removal of disease-causing parasites. Here we developed and simulated an epidemiological model describing sympatric oyster Crassostrea virginica populations in aquaculture and the wild impacted by the protozoan parasite Perkinsus marinus. Our model captured the indirect interaction between wild and cultured populations that occurs through sharing water-borne $P$. marinus transmission stages, and we hypothesized that oyster aquaculture can enhance wild oyster populations through reduced parasitism as long as cultured oysters are harvested prior to spreading disease. We found that the density of oysters in aquaculture, which is commonly thought to lead to the spread of disease through farms and out to nearby populations in the wild, has only indirect effects on $P$. marinus transmission through its interaction with the rate of aquaculture harvests. Sufficient aquaculture harvest, which varies with the susceptibility of farmed oysters to $P$. marinus infection and their lifespan once infected, reduces disease by diluting parasites in the environment. Our modeling results offer new insights toward the broader epidemiological implications of oyster aquaculture and effective disease management.
\end{abstract}

KEY WORDS: Aquaculture - Dermo disease - Disease management $\cdot$ Mathematical modeling Oyster $\cdot$ Perkinsus marinus

\section{INTRODUCTION}

Disease spread from fish and shellfish farms to sympatric fish and shellfish in the wild is a significant and contentious threat to coastal marine ecosystems (Harvell et al. 1999, Lafferty et al. 2015, Tompkins et

${ }^{*}$ Corresponding author: tbenhorin@uri.edu al. 2015). Examples such as sea lice spreading from salmon farms to wild salmon migrating out to sea (Krkošek et al. 2005, Costello 2009) and the discharge of the Rickettsia-like parasite that causes abalone withering syndrome in the effluent of shorebased abalone farms (Lafferty \& Ben-Horin 2013) restricted. Authors and original publication must be credited. 
have brought environmental groups, aquaculture and fishing industries, recreational fishing lobbies, government agencies, and scientists into direct conflict. Even as advances in aquaculture biosecurity continue to minimize disease impacts, particularly the spread of nonnative pathogens (Pali et al. 2015, Carnegie et al. 2016), it has become increasingly clear that aquaculture fundamentally changes the ecological dynamics of endemic parasites (Krkošek et al. 2005, Mikkelsen et al. 2009, Burge et al. 2016). This occurs from the logistical necessity for openwater nursery systems such as sea cages and net pens to grow many cultured species up to market size, which provides the water-borne infective stages of many marine parasites with access to an influx of new susceptible hosts. Because sites that support aquaculture are frequently occupied by or near wild conspecifics or related taxa that share diseasecausing parasites, an understanding of the broad epidemiological consequences of aquaculture will provide a starting point for conflict resolution at its interface with wild populations.

Interactions between oyster Crassostrea virginica aquaculture and wild oyster reefs present a unique case study for examining the directionality of disease spread across this interface. Wild oyster reefs were once a dominant feature of estuaries along the US Atlantic and Gulf of Mexico coasts, but have mostly declined due to overharvest and impacts from introduced and naturally occurring diseases (Beck et al. 2011, Zu Ermgassen et al. 2012). Disease controls on abundance, combined with the expansion of the USA oyster aquaculture industry in the wake of wild fishery declines (Knapp \& Rubino 2016), have since caused wild oysters to be outnumbered by their cultured conspecifics across much of this range. Beyond their commercial appeal, aquaculture, and, more recently, restoration activities have also been employed to supplement the ecological services provided by wild oyster reefs, including the removal of nutrients and organic material from the water column through the suspension feeding of oysters (Coen et al. 2007, Beck et al. 2011, Grabowski et al. 2012, Dillon et al. 2015, Humphries et al. 2016). It is also through suspension feeding that oysters are exposed to the water-borne stages of many disease-causing parasites, including the agent of dermo disease, Perkinsus marinus (Ray 1954, Allam et al. 2013, BenHorin et al. 2015). Dermo disease was first identified in the Gulf of Mexico in the 1940s (Mackin et al. 1950), and disease impacts appear to have intensified and shifted northward since the mid-1980s (Bushek \& Allen 1996, Ford \& Chintala 2006). Cultured oys- ters also experience heavy losses from disease (Dégremont et al. 2015a, Lafferty et al. 2015, Pernet et al. 2016); however, selective breeding has resulted in cultured lines with increased survival in areas where $P$. marinus is present (Dégremont et al. 2015b, Proestou et al. 2016). More recent work focused on characterizing and quantifying the response of $C$. virginica to $P$. marinus in laboratory-controlled experiments suggests that the susceptibility of oysters to $P$. marinus infection and survival rates once infected with $P$. marinus are distinct traits that vary among cultured oysters with different genetic backgrounds (Chintala et al. 2002, Ben-Horin et al. 2018). How these traits co-vary in wild and cultured oysters and across environmental gradients remains a topic of active research interest. Nevertheless, because $P$. marinus infections are chronic, with mortality often occurring 3 yr or more after initial infection (Powell et al. 2008), aquaculturists can hedge against uncertain disease risks by harvesting cultured oysters prior to the manifestation of disease-induced mortalities and further spread of $P$. marinus through farms and out to wild populations nearby. With evidence accumulating that oysters in culture remove phytoplankton and organic material from the water at rates comparable to wild populations (Dillon et al. 2015, Humphries et al. 2016), this raises the novel hypothesis that cultured oysters, if harvested before disease peaks, can reduce $P$. marinus concentrations in the water column and therefore alleviate the impact of dermo disease on sympatric wild populations.

Here we developed and simulated an epidemiological model that captured the indirect interaction through shared parasitism between sympatric oyster populations occurring in aquaculture and the wild. We hypothesized that oyster aquaculture can enhance wild oyster populations through reduced parasitism, so long as cultured oysters are harvested prior to spreading disease to wild populations. We tested this hypothesis by examining how the (1) density, (2) harvest rate, and (3) susceptibility of farmed oysters to $P$. marinus infection and lifespan, once infected, impacted the density of sympatric wild oyster populations.

\section{METHODS}

\section{Susceptible-Infected-Parasite model}

To explore how aquaculture influences disease dynamics in systems where cultured oysters interact with wild oyster populations through shared water- 
borne parasites, we generalized the SusceptibleInfected-Parasite (SIP) model of Bidegain et al. (2017), separating a wild host population into susceptible $\left(S_{W}\right)$ and infected $\left(I_{W}\right)$ classes (Fig. 1). In this model, parasite stages $(P)$ are released from the infected class into a local volume of water immediately surrounding the wild population $\left(1 \mathrm{~m}^{3}\right)$, both through the continuous shedding of parasite stages and a larger release upon mortality. Parasite stages are inactivated and/or grazed by consumers (e.g. heterotrophic microzooplankton and benthic suspension feeders other than oysters) at the per capita rate 1 . Parasites stages are also exported from the local volume of water at the per capita rate $\gamma$ and imported at the constant rate $\Gamma$. The local volume of water is filtered by susceptible and infected hosts at the constant per capita rate $\varphi_{w}$, leading to the host and parasite density-dependent removal of parasite stages from the water column. New infections occur in susceptible hosts from the parasites that are filtered out of the water at the per parasite rate of host susceptibility $\mu_{w}$.

Farming oysters adds new susceptible host classes $\left(S_{f}\right)$ at the constant stocking density per annum $\pi$, and, as with the wild population, the farmed oysters filter parasite stages from the same volume of water at the constant per capita rate $\varphi_{f}$ (Fig. 1). Since oysters used for aquaculture production often undergo selection for resistance to parasitic infection and increased survival in areas where Perkinsus marinus

A. Disease in wild populations is present (Frank-Lawale et al. 2014, Dégremont et al. 2015a, Proestou et al. 2016, Ben-Horin et al. 2018), we therefore varied the rate of infection with a perparasite rate of host susceptibility specific to the farmed population $\left(\mu_{f}\right)$. As with the wild population, infected oysters on the farm release parasite stages into the volume of water that can then be filtered by both the wild and farmed populations.

Natural mortality acts on all susceptible and infected classes by the per capita base rate $\delta$, and we supplemented this base rate in the wild population with the density-dependent loss term $c_{\boldsymbol{r}}$, which increased post-settlement mortality with increasing oyster density, fixing the carrying capacity of the wild population in the absence of disease at $(b-\delta) / c$. Conceivably, aquaculture activities such as cleaning and sorting reduce or eliminate post-settlement density-dependent sources of mortality at all but the highest population densities for aquaculture production, and we therefore did not include a densitydependent loss term in the farmed population. Harvest of the farmed population occurs at the per capita rate $\sigma$, where $\sigma^{-1}$ represents the mean time to farmed oyster harvest. Disease increases mortality in the wild and farmed infected classes by the additive rates $V_{W}$ and $v_{f}$, therefore $\left(\delta+V_{W}\right)^{-1}$ and $\left(\delta+v_{f}\right)^{-1}$ represent the mean expectation of life once wild and farmed oysters are infected with $P$. marinus in the absence of any harvest. We varied the disease mortality rate in farmed oysters $\left(v_{f}\right)$ to account for selec-

B. Disease at the aquaculture-wildlife interface

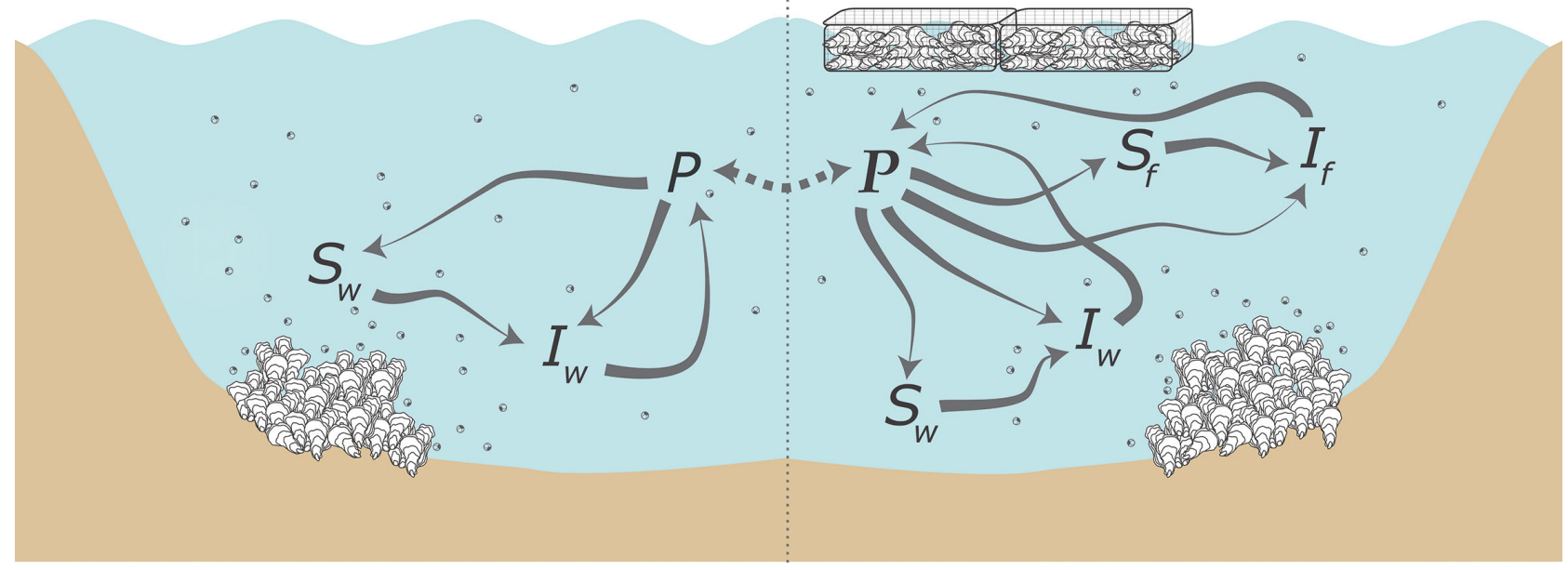

Fig. 1. The interactions between susceptible and infected host classes and water-borne parasite stages in (A) a wild oyster population in the absence of aquaculture and (B) when wild and culture populations are sympatric. The dashed line demonstrates the export and import of parasite stages between the local populations. See Table 1 for definition of parameters 
tion for increased survival in cultured stocks faced with disease. The coupled set of ordinary differential equations takes the form:

$$
\begin{gathered}
\frac{\mathrm{d} S_{W}}{\mathrm{~d} t}=b\left(S_{W}+\rho I_{W}\right)-\left(\delta+c N_{W}\right) S_{W}-\mu_{W} \varphi_{W} S_{W} P \\
\frac{\mathrm{d} I_{W}}{\mathrm{~d} t}=\mu_{w} \varphi_{W} S_{W} P-\left(\delta+v_{W}+c N_{W}\right) I_{W} \\
\frac{\mathrm{d} S_{f}}{\mathrm{~d} t}=\pi-(\delta+\sigma) S_{f}-\mu_{f} \varphi_{f} S_{f} P \\
\frac{\mathrm{d} I_{f}}{\mathrm{~d} t}=\mu_{f} \varphi_{f} S_{f} P-\left(\delta+v_{f}+\sigma\right) I_{f} \\
\frac{\mathrm{d} P}{\mathrm{~d} t}=\Gamma+\theta\left(\delta+V_{W}\right) I_{W}+\theta\left(\delta+v_{f}\right) I_{f} \\
+S\left(I_{W}+I_{f}\right)-(\mathrm{l}+\gamma) P-\left(\varphi_{W} N_{w}+\varphi_{f} N_{f}\right) P
\end{gathered}
$$

The total populations in the wild and farm are represented by $N_{W}$ and $N_{f}$, where $N_{W}=S_{W}+I_{W}$ and $N_{f}=S_{f}$ $+I_{f}$. Here, $t$ represents time in years, $b$ is the maximum birth rate per animal per year, $\rho$ is the proportional reduction in reproduction in infected classes, $\theta$ is the number of parasites released from infected hosts upon mortality, and $s$ is the per host shedding rate of infectious parasite stages into the environment.
We numerically simulated Eqs. (1) to (5) to explore how the scale of aquaculture, the rate of harvest, and the susceptibility of farmed oysters to $P$. marinus infection and survival once infected impacted concentrations of $P$. marinus in the water column and the density of wild oyster populations. We parameterized the model from relevant laboratory and field data investigating the oyster- $P$. marinus system. Detailed information concerning the parameters used in the model are presented in Table 1 . We first simulated the model for $\sigma=0: 1 \mathrm{yr}^{-1}$ and $\pi=10$ oysters $\mathrm{m}^{-2}$ (low seeding density) and $\pi=1000$ oysters $\mathrm{m}^{-2}$ (high seeding density) over $t=1000 \mathrm{yr}$, using initial population densities of $S_{W, 0}=10$ oysters $\mathrm{m}^{-2}, S_{f, 0}=0$ oysters $\mathrm{m}^{-2}$, $I_{W, 0}=10$ oysters $\mathrm{m}^{-2}, I_{f, O}=0$ oysters $\mathrm{m}^{-2}$, and $P_{0}=100$ parasites $\mathrm{m}^{-3}$ (Scenario 1). For each $\sigma$ and $\pi$ combination, we obtained the concentration of $P$. marinus in the environment and the density of the wild oyster population. We then simulated 3 additional scenarios that followed the criteria of the previous model simu-

\begin{tabular}{|c|c|c|c|c|}
\hline Term & Units & Definition & Value & Source \\
\hline \multicolumn{5}{|c|}{ State variables ${ }^{a}$} \\
\hline$S\left(S_{W} \& S_{f}\right)$ & oysters $\mathrm{m}^{-2}$ & Density of susceptible wild $(w)$ and farmed $(f)$ hosts & & \\
\hline$I\left(I_{W} \& I_{f}\right)$ & oysters $\mathrm{m}^{-2}$ & Density of infected hosts & & \\
\hline$P$ & parasites $\mathrm{m}^{-3}$ & Concentration of parasites in the environment & & \\
\hline \multicolumn{5}{|l|}{ Parameters } \\
\hline$b$ & $\mathrm{yr}^{-1}$ & Maximum birth rate of hosts & 0.73 & Powell et al. (2009) \\
\hline$\rho$ & - & Relative fecundity of infected hosts & 0.5 & Paynter (1996) \\
\hline$\delta$ & $\mathrm{yr}^{-1}$ & Natural mortality rate of hosts & 0.11 & Powell et al. (2009) \\
\hline$\mu_{w}$ & oysters parasite $^{-1}$ & Per-parasite host susceptibility (wild population) & 0.0002 & Chu \& Volety (1997) \\
\hline$\mu_{f}$ & oysters parasite ${ }^{-1}$ & Per-parasite host susceptibility (farmed population) & varies & \\
\hline$V_{W}$ & $\mathrm{yr}^{-1}$ & Disease mortality rate (wild population) & 0.29 & Bushek et al. (2012) \\
\hline$V_{f}$ & $\mathrm{yr}^{-1}$ & Disease mortality rate (farmed population) & varies & \\
\hline$\varphi_{W}$ & $\mathrm{~m}^{3}$ oyster ${ }^{-1} \mathrm{yr}^{-1}$ & Host filtration rate (wild population) & 30.0 & Riisgård (1988) \\
\hline$\varphi_{f}$ & $\mathrm{~m}^{3}$ oyster ${ }^{-1} \mathrm{yr}^{-1}$ & Host filtration rate (farmed population) & varies $^{\mathrm{b}}$ & \\
\hline $\mathrm{C}$ & $\mathrm{m}^{3}$ oyster ${ }^{-1}$ & Density dependent parameter & 0.002067 & $\begin{array}{l}\text { Powell et al. (2009), } \\
\text { Powell et al. (2012) }\end{array}$ \\
\hline$\theta$ & parasites oyster $^{-1}$ & Parasites released from infected oysters upon death & 10000 & Diamond (2012) \\
\hline$s$ & $\mathrm{yr}^{-1}$ & Shedding rate of parasite from infected hosts & 2550 & Bushek et al. (2002) \\
\hline$\pi$ & oysters $\mathrm{yr}^{-1}$ & Aquaculture seeding rate & varies & \\
\hline 1 & $\mathrm{yr}^{-1}$ & Inactivation and loss rate of free-living parasites & 52.0 & Soudant et al. (2005) \\
\hline$\sigma$ & $\mathrm{yr}^{-1}$ & Aquaculture harvest rate & varies & \\
\hline \multicolumn{5}{|c|}{$\begin{array}{l}\text { 'The farmed population is harvested and therefore 'younger' and 'smaller' than the population in the wild. As bivalve } \\
\text { filtration rates scale with body size and therefore age, } \varphi_{f} \text { declined with the aquaculture harvest rate } \sigma \text { according to the } \\
\text { exponential decay function } \varphi_{f}=35.79 \mathrm{e}^{-1.33 \sigma}\end{array}$} \\
\hline
\end{tabular}
lation but varied the susceptibility of farmed oysters to $P$. marinus infection and survival once infected. In Scenario 2, we simulated the model planting oysters on the farm with decreased susceptibility to infection

Table 1. State variables and parameters used in the epidemiological model 
with P. marinus. Scenario 3 planted oysters with increased survivorship given infection, and Scenario 4 planted oysters with decreased susceptibility and increased survivorship. For each scenario we again obtained the equilibrium concentration of $P$. marinus in the environment and the density of the wild oyster population for each parameter combination.

\section{RESULTS}

\section{Analytical solutions to the SIP model}

We first evaluated the impact of aquaculture on wild oyster populations from the equilibrium solutions for total density $\left(N^{*}\right)$ and infection prevalence $\left(i^{*}\right)$ of the wild and farmed populations, where $S_{w}=$ $\left(1-i_{W}\right) N_{W}$ and $I_{W}=i_{W} N_{W}$ and $S_{f}=\left(1-i_{f}\right) N_{f}$ and $I_{f}=$ $i_{f} N_{f}$. After some transformations (see the Supplement at www.int-res.com/articles/suppl/q010p557_supp. pdf), we calculated the density of the wild population at the endemic disease equilibrium $\left(N_{w}\right)$ :

where

$$
N_{W}^{*}=\frac{b-\delta+i_{W}^{*}\left(b \rho-b-V_{W}\right)}{C}
$$

$$
i_{W}^{*}=\frac{\frac{\pi}{N_{f}^{*}}-\delta-\sigma}{v_{f}}
$$

The ratio $\Omega$ in the denominator of Eq. (7) describes the proportional change in the equilibrium prevalence of infection in the farmed population relative to the population in the wild (i.e. $\Omega=\frac{i_{f}^{*}}{i_{W}^{*}}$ ). This solution provided 3 important insights into the potential impact of aquaculture on wild populations when parasites are shared: (1) the term at the right of Eq. (6) $\left(b \rho-b-v_{w}\right.$ ) will always be negative because $\rho \leq 1$; therefore, activities that increase the prevalence of infection in wild populations $\left(i_{w}^{*}\right)$ will, as expected, drive down population density; (2) since $\mathrm{n}_{f}^{*}$ increases with increasing stocking density of farmed oysters $(\pi)$, the effects of increasing stocking densities in aquaculture on $i_{\mathrm{w}}^{*}$, and hence $N_{\mathrm{w}}^{*}$, are neutral; and (3) increasing the harvest rate of farmed oysters will decrease $i_{\mathrm{w}}^{*}$.

We then evaluated how aquaculture influences disease dynamics at the interface of cultured and wild populations. We assumed that the export of parasite stages from the local volume of water was balanced by parasites imported $(\Gamma=\gamma P)$, which would approximate cases of extensive aquaculture and at the immediate interface of cultured and wild populations. Using the next-generation matrix approach of
Diekmann et al. (2010) to define the parasite's basic reproductive number at the disease-free equilibrium $\left(R_{0}\right)$ for the population at the farm $\left(R_{0, f} ; S_{f} \approx N_{f}, I_{f}=0\right.$, $\mathrm{p}=0$; see the Supplement), we found the condition for disease persistence:

$$
R_{0, f}=\sqrt{\frac{\mu_{f} \varphi_{f} N_{f}\left[\theta\left(\delta+v_{f}\right)+s\right]}{\left(1+\varphi_{f} N_{f}\right)\left(\delta+v_{f}+\sigma\right)}}>1
$$

We interpreted $R_{0, f}$ as the product of (1) the probability that infectious parasite stages contact hosts before they die (a function that saturates with host density $\left.\mu_{f} \varphi_{f} N_{f} /\left(1+\varphi_{f} N_{f}\right)\right)$ and (2) the number of infectious stages produced over an infected host's life $\left(\left(\theta\left(\delta+v_{f}\right)\right.\right.$ $\left.+s) /\left(\delta+v_{f}+\sigma\right)\right)$. In the case of the farmed population, $R_{0, f}$ can be used to quantify how aquaculture can amplify or dilute disease risks. Increased susceptibility to Perkinsus marinus infection $\left(\mu_{f}\right)$ in planted oysters increases $R_{0, f}$ by increasing the probability that parasite stages will induce successful infections. The consequences of variation in the expected lifespan of oysters with P. marinus infection are less straightforward. The lifetime production of infectious stages reflects a balance between parasites released by hosts and host removal through mortality and harvest. While the benefit of increased survival in cultured populations is clear (i.e. they carry a parasite load with no adverse effects on survival), this benefit may come to the detriment of their wild counterparts. Oysters that survive with $P$. marinus infection for longer periods of time potentially release more parasites into the surrounding water, and the 'excess' parasites can be transmitted to sympatric wild populations. The greatest disease risk occurs when the planted oysters are harvested slowly, or not at all (Fig. 2). The latter is the case with extensive on-bottom oyster planting as well as with efforts to restore oyster reefs by planting oysters in no-harvest oyster sanctuaries (Coen et al. 2007), and this highlights the need to account for the direct and indirect consequences associated with the traits of planted stocks with respect to the goals of aquaculture or restoration.

\section{Numerical simulations of the SIP model}

The introduction of oyster aquaculture in the model led to changes in both the equilibrium concentration of $P$. marinus in the environment and the density of the wild oyster population, for better and for worse. For Scenario 1, where the density of oysters stocked each year $(\pi)$ and the aquaculture harvest rate $(\sigma)$ were varied (but wild and cultured oysters were equally susceptible to infection and disease 


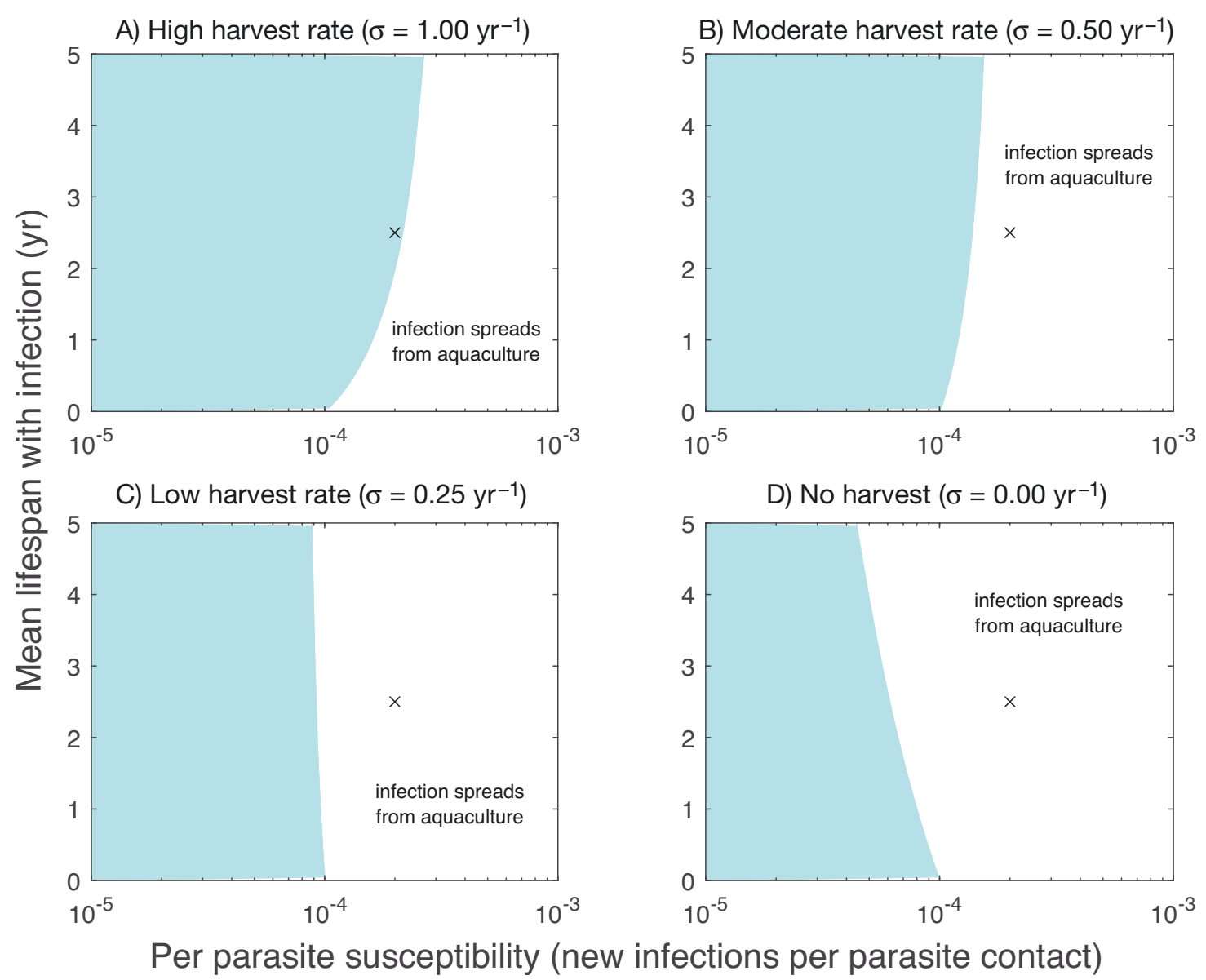

Fig. 2. Isoclines showing the threshold for disease emergence $\left(R_{0, f}>1\right.$ to the right of each isocline, see Table 1 for parameter definitions) as a function of the susceptibility of planted oysters to Perkinsus marinus infection $\left(\mu_{f}\right)$, the expected lifespan of planted oysters once infected with $P$. marinus $\left(1 / \delta+v_{f}\right)$, and the aquaculture harvest rate (A-D). The ' $x$ ' in each plot indicates the values of $\mu_{w}$ and $\left(1 / \delta+V_{w}\right)$ of the wild oyster population. Both with and without harvest, increasing the susceptibility of planted oysters to $P$. marinus infection increases the spread of infection from aquaculture. In the absence of harvest, increasing the lifespan of planted oysters infected with $P$. marinus leads to a counterintuitive increase in the spread of infection from aquaculture

mortality), the threshold between better (i.e. aquaculture has a positive effect on wild populations) and worse (i.e. aquaculture has a negative effect on wild populations) occurred at a harvest rate of $0.62 \mathrm{yr}^{-1}$ (mean time to harvest $\approx 19 \mathrm{mo}$ ), regardless of the density oysters were stocked on the farm. Sufficient harvest of the oysters stocked on the farm $(\sigma>$ $0.62 \mathrm{yr}^{-1}$ ) led to a decrease in environmental concentrations of $P$. marinus (Fig. 3A; left panel), which in turn led to an increase in the density of the wild oyster population (Fig. 3A; right panel). Increasing the density of oysters stocked on the farm increased this benefit, both in terms of the parasites removed from the environment and the increase in wild population density. Below the threshold harvest rate of $0.62 \mathrm{yr}^{-1}$, the introduction of aquaculture increased water column concentrations of $P$. marinus and decreased the density of wild oysters. Like the effects seen above this threshold value, increasing the stocking density of aquaculture increased the magnitude of this effect. These results mirror the solution to the parasite's basic reproductive number for the population at the farm (Eq. 8), where we found transmission to respond directly to the aquaculture harvest rate, whereas the aquaculture stocking density had only indirect effects on $R_{0}$ through its effect on $N_{f}$. This both supports and contradicts expectations of the epidemiological effects of increasing stocking densities in aquaculture, such as the demonstrated increase in parasitic sea lice in the nearshore waters adjacent to salmon farms (Jansen et al. 2012). Given our model representation of the transmission dynamics between oyster aquaculture and wild oyster populations, increases in the stocking density alone cannot drive the 


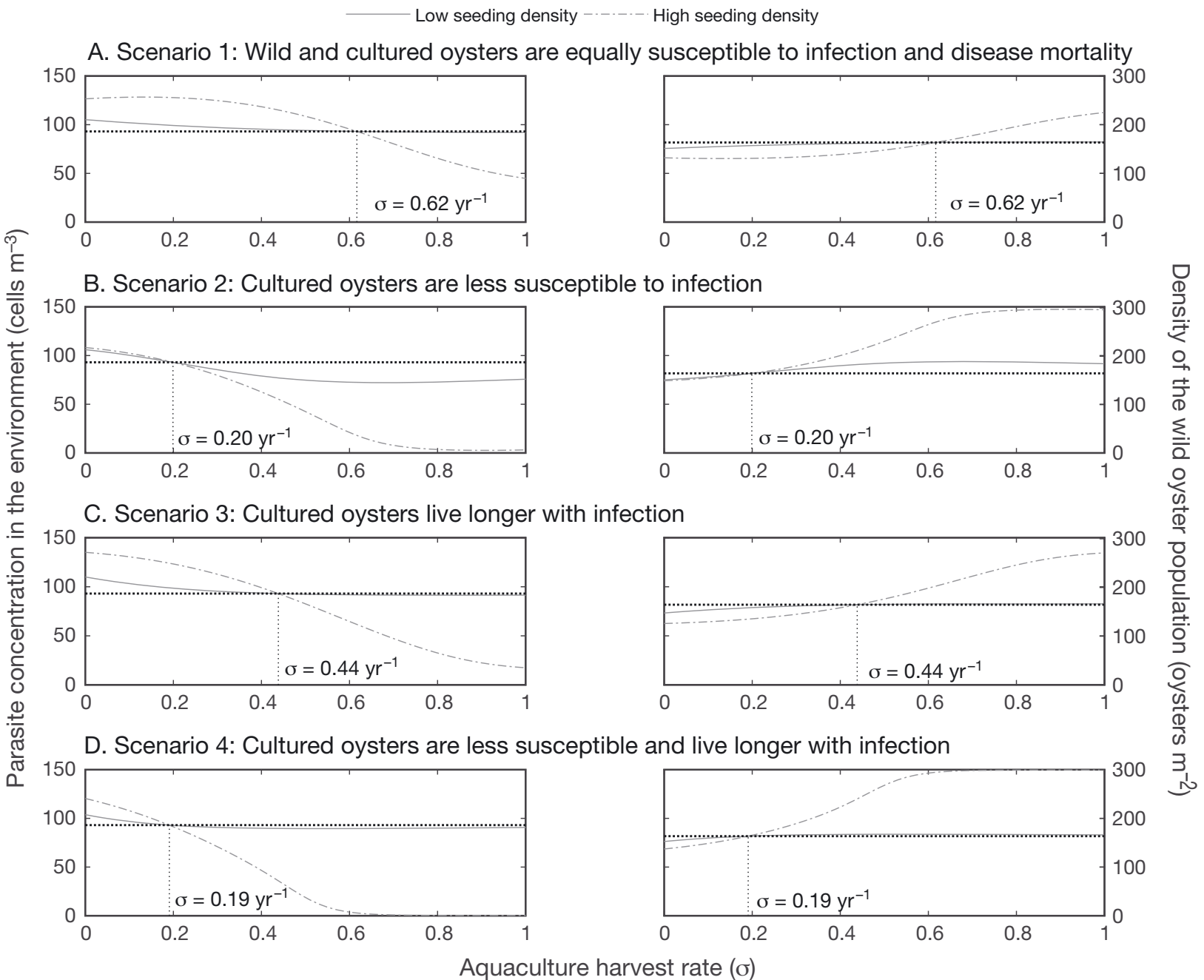

Fig. 3. Equilibrium concentration of Perkinsus marinus in the environment (left column) and the density of wild oyster populations (oysters $\mathrm{m}^{-2}$ ) as a function of the aquaculture harvest rate $(\sigma)$. Solid lines: aquaculture planting rate $(\pi)$ of 10 oysters $\mathrm{m}^{-2}$ $\mathrm{yr}^{-1}$; dashed lines: planting rate of 1000 oysters $\mathrm{m}^{-2} \mathrm{yr}^{-1}$; horizontal dotted lines: the equilibrium concentration of $P$. marinus in the environment and density of the wild oyster population in the absence of aquaculture; vertical dotted lines: the threshold values of the aquaculture harvest rate that lead to a decrease in parasite concentrations in the environment and an increase in the density of the wild oyster population. For the simulated Scenarios 1 to 4 , increasing the aquaculture harvest rate increased the density of the wild oyster population

spread of disease. Instead, the aquaculture stocking density interacts with other activities, here the harvest rate, to drive the dynamics of disease at the interface of aquaculture and wild populations.

Varying the susceptibility of planted oysters to $P$. marinus infection and survivorship of oysters infected with $P$. marinus further modified disease dynamics. In line with our prediction from the relationship between susceptibility to $P$. marinus infection and $R_{0, f}$ decreasing the susceptibility of the planted stock to $P$. marinus infection led to further decreases in the equilibrium concentrations of $P$. marinus in the water column (Fig. 3B; left panel), and in turn increased in the density of wild oysters (Fig. 3B; right panel). The threshold harvest rate where aquaculture transi- tioned from exerting a negative effect on wild populations to a positive one decreased with decreased susceptibility to $P$. marinus infection, occurring when $\sigma=$ $0.20 \mathrm{yr}^{-1}$ (mean time to harvest $=5 \mathrm{yr}$ ) in Scenario 2 . Oysters less susceptible to infection with $P$. marinus can therefore remain on the farm longer without spreading disease to wild populations. Increases in the survival of planted oysters infected with $P$. marinus (Scenario 3) were less straightforward. When the aquaculture harvest rate was sufficiently high $(\sigma>$ $0.44 \mathrm{yr}^{-1}$; mean time to harvest $<15 \mathrm{mo}$ ), increasing the survival of planted oysters infected with $P$. marinus had a slightly positive effect on the wild oyster population, decreasing parasite concentrations in the environment (Fig. 3C; left panel) and increasing 
wild population densities (Fig. 3C; right panel). When the aquaculture harvest rate was low, farmed oysters remained in the water for longer periods of time and increases in the survival rate of the planted stock were met with increases in environmental parasite concentrations and decreases in the density of the wild oyster population. In fact, when the planted stock was not harvested, increases in the expected lifespan with $P$. marinus infection in the planted stock led to a relative increase in parasite concentrations in the environment, and a relative decrease in the density of the wild oyster population when compared to Scenario 1 . The interactive effects of varying the harvest rate and survival of the planted stock on parasite concentrations in the environment and the density of wild oysters mirrored our previous finding demonstrating $R_{0, f}$ to respond directly to the aquaculture harvest rate. Increasing the lifespan of planted oysters infected with $P$. marinus increased the lifetime production of parasite stages, and therefore, amplified $R_{0, f}$ when the aquaculture harvest rate was low. In the solutions to the model, increasing survival similarly led to an increase in environmental concentrations of $P$. marinus and a decrease in the density of wild oysters. These results underscore the value of understanding the consequences of selective breeding for traits such as susceptibility to parasitic infection and survival given infection in aquaculture. The goal of selective breeding is to maximize production in the face of disease risk. However, our results indicate that the selection for various traits associated with the performance of aquaculture stocks facing disease can have widely different outcomes on the dynamics of disease when outcomes extend to sympatric wild populations.

\section{DISCUSSION}

Open-water oyster aquaculture will reduce disease in sympatric populations when cultured populations deter disease agents from infecting hosts in the wild, either by serving as incompetent decoys for parasite stages (Johnson \& Thieltges 2010), or, as demonstrated here, when serving as hosts themselves so long as they are harvested before disease peaks. The rate at which cultured populations are harvested is therefore critically important and leads to different disease outcomes with increases in the stocking density of aquaculture. In salmon aquaculture, for example, increases in the aquaculture stocking density appear to amplify levels of parasitic sea lice in the nearshore waters adjacent to farms (Jansen et al. 2012). However, in the case of salmon, aquaculture fundamentally changes the transmission dynamics of sea lice. The logistical necessity to confine farmed adult salmon within nearshore sea cages held in the same location for extended periods of time leads to a magnification in sea louse transmission that generally increases with increasing densities of salmon farms (Costello 2006, Jansen et al. 2012). The culture of oysters and other bivalves similarly occurs in openwater sea cages, but the transmission dynamics of parasites such as Perkinsus marinus are relatively unchanged whether oyster populations are in culture or in the wild (Burreson \& Ragone Calvo 1996). Therefore, increasing oyster densities leads to an increase in both the probability that infectious parasite stages contact potential hosts as well as an increase in the removal of parasite stages from the environment (Eq. 8). This duality leads to idiosyncratic effects of increasing aquaculture stocking densities on parasite spread (i.e. $R_{0}$ ) and the density of wild oysters. In our model representation of the oyster$P$. marinus system, parasite densities in the environment increased and the density of wild populations decreased with increases in the stocking density of aquaculture, but only when the harvest rate of aquaculture was low. The opposite occurred when aquaculture harvest was sufficiently high, where increasing stocking densities increased the removal of parasites from the environment and increased the density of sympatric wild oysters.

The central role played by the rate of aquaculture harvests has clear implications for disease management. Increasing the duration that cultured oysters remain in an estuary increases the likelihood of transmission in addition to the number of parasites hosts produce. Reductions in the growth rates of cultured oysters, such as those occurring as unintended trade-offs when selecting for other desirable traits (Dégremont et al. 2010, 2015b), will tend to increase disease if oysters are harvested at similar size and age. While oyster farmers would seldom aim to reduce growth rates, they may be faced with choices that lead to this consequence. For example, growing oysters on the bottom rather than suspended in cages would have this effect (Castagna et al. 1996). Similarly, interest from the aquaculture industry in growing thicker-shelled oysters to improve the marketability of half-shell products may lead to slower growth. The thin shells of fast-growing domesticated oyster lines fragment easily when opened and are readily penetrated by boring polydorid worms to the detriment of product quality and sales (Morse et al. 2015). Oysters genetically selected or manipulated through culture methods to produce heavier shells to 
mitigate these issues would be likely to grow more slowly and require a delayed harvest. Furthermore, the intensive culture of oysters in cages or trays permits the complete harvest of a cohort on some schedule, which can be managed. The extensive culture of oysters on the seabed free of any containment, a practice still in wide use, precludes complete harvest, increasing parasite transmission and its adverse effects on wild populations at any rate of planting. Promoting intensive (i.e. contained) oyster culture and shorter harvest schedules would therefore reduce the probability that oyster aquaculture facilitates disease in wild populations.

Our results also have direct implications for efforts to restore wild oysters by stocking wild or reconstructed reefs with hatchery-produced oysters, a common practice wherever oyster restoration occurs (Coen et al. 2007). In this application, planted oysters are not harvested at all, so the direct benefits to wild oysters nearby that occurs through increased reproduction and recruitment (which may be questionable in the first place; see Hare et al. 2006) may come with indirect increases in disease. All restored oyster reefs eventually develop infection profiles that mirror those of surrounding natural populations (Mann \& Powell 2007). However, because restored reefs are not harvested, restoration may lead to a local increase in the equilibrium state of disease, and a decrease, in turn, in the density of local oyster populations. This outcome may be more likely if the oysters planted for restoration are selected to survive but not resist infection. Such an outcome would oppose the goals of restoration itself, highlighting the need to consider the direct and indirect consequences associated with the traits of planted oysters with respect to the goals of restoration.

Our conclusions are drawn from a model hostparasite system, and this naturally raises the question of field testing. Some of the predictions from our model, such as effects of aquaculture on equilibrial dynamics in wild oyster populations, are difficult to test because they simulate interactions between aquaculture and wild populations for long periods in the absence of acute disturbance or changes in human behavior. However, our conclusions offer testable predictions of the role of aquaculture in driving the dilution and/or spread of parasites in coastal waters. Can regularly harvested oyster farms serve as a sink for disease-causing parasites? Alternatively, do parasites spread in the absence of harvest (e.g. oyster restoration sites)? Data on the behavior and distribution of planktonic parasite stages, including ecological interactions occurring in the plankton, can be integrated into Lagrangian particle tracking models to directly test model predictions in the field. How oyster aquaculture and restoration activities fit into the seascape of disease risk within and across estuaries offers a rich area for future research.

The consumption of parasites can dramatically alter disease dynamics (Civitello et al. 2013, Bidegain et al. 2016). Using a unique case study where wild and farmed hosts are also consumers of parasites, we suggest that oyster aquaculture fundamentally changes the dynamics of an endemic disease. Aquaculture can serve either as a source or sink of diseasecausing parasites of wild oyster populations depending on management variables such as the stocking density, harvest rate of aquaculture, and traits of the planted stock. As our case study illustrates, a fuller accounting of the ecological processes involved in the interactions between cultured and wild populations provides a novel framework for predicting disease outcomes arising from human activities in coastal marine ecosystems.

Data archive. MATLAB (The MathWorks) scripts simulating the epidemiological model are available at https://zenodo. org/record/2004192.

Acknowledgements. P. Hershberger and K. Lafferty provided constructive comments on an earlier draft of the manuscript. This work was conducted as part of the Ecology of Infectious Marine Disease Research Coordination Network (www.eeb.cornell.edu/ecologymarinedisease/html) funded by the National Science Foundation Ecology and Evolution of Infectious Diseases grant OCE-1215977. T.B.H. was supported by a USDA-NIFA Postdoctoral Fellowship (RI000912). This work was further supported by the USDA National Institute of Food and Agriculture Hatch project accession number 1009201 through the New Jersey Agricultural Experiment Station, Hatch project NJ32114, and the Virginia Institute of Marine Science (VIMS) Endowment A. Marshall Acuff, Sr. Memorial Endowment for Oyster Disease Research. This is VIMS contribution number 3795.

\section{LITERATURE CITED}

Allam B, Carden WE, Ward JE, Ralph G, Winnicki S, Pales Espinosa E (2013) Early host-pathogen interactions in marine bivalves: evidence that the alveolate parasite Perkinsus marinus infects through the oyster mantle during rejection of pseudofeces. J Invertebr Pathol 113: 26-34

* Beck MW, Brumbaugh RD, Airoldi L, Carranza A and others (2011) Oyster reefs at risk and recommendations for conservation, restoration, and management. Bioscience 61: 107-116

Ben-Horin T, Bidegain G, Huey L, Narvaez DA, Bushek D (2015) Parasite transmission through suspension feeding. J Invertebr Pathol 131:155-176

Ben-Horin T, Allen SK Jr, Small JM, Proestou DA (2018) 
Genetic variation in anti-parasite behavior in oysters. Mar Ecol Prog Ser 594:107-117

Bidegain G, Powell EE, Klinck JM, Ben-Horin T, Hofmann EE (2016) Marine infectious disease dynamics and outbreak thresholds: contact, transmission, pandemic infection, and the potential role of filter feeders. Ecosphere 7 : e01286

Bidegain G, Powell EN, Klinck JM, Hofmann EE and others (2017) Modeling the transmission of Perkinsus marinus in the eastern oyster Crassostrea virginica. Fish Res 186: 82-93

* Burge CA, Closek CJ, Friedman CS, Groner ML, Jenkins CM, Shore-Maggio A, Welsh JE (2016) The use of filterfeeders to manage disease in a changing world. Integr Comp Biol 56:573-587

Burreson EM, Ragone Calvo LM (1996) Epizootiology of Perkinsus marinus disease of oysters in Chesapeake Bay, with emphasis on data since 1985. J Shellfish Res 15:17-34

Bushek D, Allen SK Jr (1996) Host-parasite interactions among broadly distributed populations of the eastern oyster Crassostrea virginica and the protozoan Perkinsus marinus. Mar Ecol Prog Ser 139:127-141

Bushek D, Ford SE, Chintala MM (2002) Comparison of in vitro-cultured and wild-type Perkinsus marinus. III. Fecal elimination and its role in transmission. Dis Aquat Org 51:217-225

* Bushek D, Ford SE, Burt I (2012) Long-term patterns of an estuarine pathogen along a salinity gradient. J Mar Res 70:225-251

Carnegie RB, Arzul I, Bushek D (2016) Managing mollusk diseases in the context of regional and international commerce: policy issues and emerging concerns. Philos Trans R Soc B 371:20150215

Castagna MM, Gibbon MC, Kurkowski K (1996) Culture: application. In: Kennedy VS, Newell RIE, Eble A (eds) The eastern oyster Crassostrea virginica. Publication UM-SG-TS-96-01. Maryland Sea Grant College, College Park, MD, p 675-690

Chintala MM, Bushek D, Ford SE (2002) Comparison of in vitro-cultured and wild-type Perkinsus marinus II: Dosing methods and host response. Dis Aquat Org 51:203-216

Chu FLE, Volety AK (1997) Disease processes of the parasite Perkinsus marinus in eastern oyster Crassostrea virginica: minimum dose for infection initiation, and interaction of temperature, salinity and infective cell dose. Dis Aquat Org 28:61-68

* Civitello DJ, Pearsall S, Duffy MA, Hall SR (2013) Parasite consumption and host interference can inhibit disease spread in dense populations. Ecol Lett 16:626-634

* Coen LD, Brumbaugh RD, Bushek D, Grizzle R and others (2007) Ecosystem services related to oyster restoration. Mar Ecol Prog Ser 341:303-307

C Costello MJ (2006) Ecology of sea lice parasites on farmed and wild fish. Trends Parasitol 22:475-483

* Costello MJ (2009) How sea lice from salmon farms may cause wild salmonid declines in Europe and North America and be a threat to fishes elsewhere. Proc R Soc B 276: 3385-3394

Dégremont L, Bédier E, Boudry P (2010) Summer mortality of hatchery-produced Pacific oyster spat (Crassostrea gigas). II. Response to selection for survival and its influence on growth and yield. Aquaculture 299:21-29

¿Dégremont L, Garcia C, Allen SK Jr (2015a) Genetic improvement of disease resistance in oysters: a review. J Invertebr Pathol 131:226-241
Dégremont L, Lamy JB, Pépin JF, Travers MA, Renault T (2015b) New insight for the genetic evaluation of resistance to ostreid herpesvirus infection, a worldwide disease, in Crassostrea gigas. PLOS ONE 10:e0127917

Diamond EA (2012) Do scavengers influence dermo disease (Perkinsus marinus) transmission? MS thesis, Rutgers, The State University of New Jersey

* Diekmann O, Heesterbeek JAP, Roberts MG (2010) The construction of next-generation matrices for compartmental epidemic models. J R Soc Interface 7:873-885

Dillon KS, Peterson MS, May CA (2015) Functional equivalence of constructed and natural intertidal eastern oyster reef habitats in a northern Gulf of Mexico estuary. Mar Ecol Prog Ser 528:187-203

Ford SE, Chintala MM (2006) Northward expansion of a marine parasite: testing the role of temperature adaptation. J Exp Mar Biol Ecol 339:226-235

Frank-Lawale A, Allen SK Jr, Dégremont L (2014) Breeding and domestication of eastern oyster (Crassostrea virginica) lines for culture in the mid-Atlantic, USA: Line development and mass selection for disease resistance. J Shellfish Res 33:153-165

*Gabowski JH, Brumbaugh RD, Conrad RF, Keeler AG and others (2012) Economic valuation of ecosystem services provided by oyster reefs. Bioscience 62:900-909

Hare MP, Allen SK Jr, Bloomer P, Camara MD and others (2006) A genetic test for recruitment enhancement in Chesapeake Bay oysters, Crassostrea virginica, after population supplementation with a disease tolerant strain. Conserv Genet 7:717-734

Harvell CD, Kim K, Burkholder JM, Colwell RR and others (1999) Emerging marine diseases: climate links and anthropogenic factors. Science 285:1505-1510

*Humphries AT, Ayvazian SG, Carey JC, Hancock BT and others (2016) Directly measured denitrification reveals oyster aquaculture and restored oyster reefs remove nitrogen at comparable rates. Front Mar Sci 3:74

Jansen PA, Kristoffersen AB, Viljugrein H, Jimenez D, Aldrin M, Stien A (2012) Sea lice as a density-dependent constraint to salmonid farming. Proc R Soc B 279:2330-2338

* Johnson PTJ, Thieltges DW (2010) Diversity, decoys and the dilution effect: how ecological communities affect disease risk. J Exp Biol 213:961-970

Knapp G, Rubino MC (2016) The political economics of marine aquaculture in the United States. Rev Fish Sci Aquacult 24:213-229

KKrkošek M, Lewis MA, Volpe JP (2005) Transmission dynamics of parasitic sea lice from farm to wild salmon. Proc R Soc B 272:689-696

Lafferty KD, Ben-Horin T (2013) Abalone farm discharges the withering syndrome pathogen into the wild. Front Microbiol 4:373

* Lafferty KD, Harvell CD, Conrad JM, Friedman CS and others (2015) Infectious diseases affect marine fisheries and aquaculture economics. Ann Rev Mar Sci 7:471-496

*Mackin JG, Owen HM, Collier A (1950) Preliminary note on the occurrence of a new protistan parasite, Dermocystidium marinum sp. in Crassostrea virginica (Gmelin). Science 111:328-329

*Mann R, Powell EN (2007) Why oyster restoration goals in the Chesapeake Bay are not and probably cannot be achieved. J Shellfish Res 26:905-917

*Mikkelsen H, Lund V, Børdal S, Schrøder MB (2009) Challenge model for effluent mediated transmission of diseases between fish species. Aquaculture 287:388-394 
Morse DL, Rawson PD, Kraeuter JN (2015) Mud blister worms and oyster aquaculture. Maine Sea Grant and the University of Maine, Orono, ME

Pali D, Scarfe AD, Walster CI (2015) National and international aquaculture biosecurity requirements for preventing, controlling, and eradicating infectious diseases. J Appl Aquacult 27:185-219

Paynter KT (1996) The effects of Perkinsus marinus infection on physiological processes in the eastern oyster, Crassostrea virginica. J Shellfish Res 15:119-125

Pernet F, Lupo C, Bacher C, Whittington RJ (2016) Infectious diseases in oyster aquaculture require a new integrated approach. Philos Trans R Soc B 371:20150213

Powell EN, Ashton-Alcox KA, Kraeuter JN, Ford SE, Bushek D (2008) Long-term trends in oyster population dynamics in Delaware Bay: regime shifts and response to disease. J Shellfish Res 27:729-755

Powell EN, Klinck JM, Ashton-Alcox KA, Kraeuter JN (2009) Multiple stable reference points in oyster populations: implications for reference point-based management. Fish Bull 107:133-147

Powell EN, Klinck JM, Ashton-Alcox K, Hofmann EE, Morson J (2012) The rise and fall of Crassostrea virginica oyster reefs: The role of disease and fishing in their demise and a

Editorial responsibility: Peter Cranford,

Dartmouth, Nova Scotia, Canada vignette on their management. J Mar Res 70:505-558

* Proestou DA, Vinyard BT, Corbett RJ, Piesz J and others (2016) Performance of selectively-bred lines of eastern oyster, Crassostrea virginica, across eastern US estuaries. Aquaculture 464:17-27

Ray SM (1954) Biological studies of Dermocystidium marinum, a fungus parasite of oysters. Rice Institute, Houston, TX

Riisgård HU (1988) Efficiency of particle retention and filtration rate in 6 species of Northeast American bivalves. Mar Ecol Prog Ser 45:217-223

* Soudant P, Chu FLE, Lund ED (2005) Assessment of the cell viability of cultured Perkinsus marinus (Perkinsea), a parasitic protozoan of the eastern oyster, Crassostrea virginica, using SYBR green - propidium iodide double staining and flow cytometry. J Eukaryot Microbiol 52: 492-499

Tompkins DM, Carver S, Jones ME, Krkošek M, Skerratt LF (2015) Emerging infectious diseases of wildlife: a critical perspective. Trends Parasitol 31:149-159

Zu Ermgassen PSE, Spalding MD, Blake B, Coen LD and others (2012) Historical ecology with real numbers: past and present extent and biomass of an imperiled estuarine habitat. Proc R Soc B 279:3393-3400

Submitted: July 18, 2018; Accepted: October 22, 2018

Proofs received from author(s): December 6, 2018 